\title{
LA IMPORTANCIA DE RENATO TREVES EN LOS ORÍGENES INSTITUCIONALES DE LA SOCIOLOGÍA JURÍDICA ITALIANA
}

\author{
Sergio PÉREZ GONZÁLEZ \\ INVESTIGADOR, FILOSOFÍA DEL DERECHO \\ UNIVERSIDAD DE LA RIOJA
}

s $\quad$ u m a r i o

I. Introducción 2. Recomposición de los precedentes científicos 3. Ámbito académico 4. Primeras publicaciones tras el fascismo 5. Movimiento asociativo 6. Conclusiones.

r e s u m e $\mathbf{n}$

El artículo pone de manifiesto la relevancia del filósofo y sociólogo del derecho Renato Treves en la fase inicial de la institucionalización de la sociología jurídica como ciencia autónoma en Italia, diferenciada sea de la sociología, sea de la ciencia jurídica. Para ello se revisan la bibliografía y actividades del autor italiano, dotándolas de sentido en cuanto al objetivo previsto. Se encauza en esta dirección, por tanto, su aportación teórica para superar las trabas de la tradición así como su empeño práctico, asociativo y académico.

\section{Introducción}

Mediante estas breves anotaciones pretendemos dar cuenta de la labor impulsora fundamental que para la sociología del derecho italiana desarrolló el jurista Renato Treves, para lo cual, y a modo de escenario de fondo, debemos tener en consideración las circunstancias del tiempo y lugar en el que el empeño de Treves se hace aún más relevante: la Italia de posguerra.

El legado del fascismo había sido, básicamente, un panorama desolador en todos los órdenes, transcendiendo más allá de los daños directos de la guerra en el plano económico y social. La actividad intelectual y académica en el país transalpino lastraba 
desde hacía decenios con las tendencias impuestas por el poder político, de manera que la ciencia sociojurídica permanecía aún en estado embrionario, subyugada en parte por la tradición idealista italiana, tradición caricaturesca en los años de fascismo y aún más al ser imbuida en la política propagandística de guerra.

Renato Treves (I907-I992) había bebido de esas mismas fuentes del omnipresente neoidealismo italiano, de modo que su labor impulsora se configura no sólo como una lucha frente a las circunstancias externas, sino incluso como una voluntariosa evolución personal desde la propia formación académica inicial.

Treves, de origen judío, había debido salir del país en I938. Su exilio en Argentina resultó una etapa crucial en el propio devenir intelectual y profesional (en la universidad argentina de Tucumán ejerció como profesor de sociología), pero los retos no habían sino empezado.

Su vuelta a Italia en I948 le devuelve a un país en crisis y, por tanto, a un país por reconstruir también en el plano intelectual y académico. Las inquietudes adquiridas por Treves -dirigidas hacia la sociología (ya apuntadas en sus primeros años de formación y ratificadas en el exilio) - le llevan a fomentar, a su regreso, el desarrollo de la autonomía de la sociología jurídica como ciencia suficientemente diferenciada. Treves emprende esta labor abordando varias facetas orientadas a un mismo fin.

\section{Recomposición de los precedentes científicos}

A partir de la década de los cincuenta Treves recompone buena parte de la tradición italiana en aras de sentar las bases para el desarrollo de la sociología jurídica; se refiere al elemento científico en cuanto rescata las incursiones científicas que otros autores realizaron en el ámbito de la sociología y la sociología jurídica anteriormente, tomando como referencias fundamentales a Vico, Romagnosi o Cattaneo (aunque éstos quizás más como símbolos que como argumentos de ciencia) (TREVES I982b). No insinuamos que reinventa el pasado, pero al menos, en su labor articulista de aquellos años, propone una relectura de varios autores italianos que hasta entonces permanecían como realidad oculta tras la cortina idealista. Treves realiza una «ficción inductora» hacia la sociología jurídica, ya que, salvando la referencia a las primeras inquietudes de su maestro Gioele Solari, a lo largo de su obra no se refiere apenas a la labor de los positivistas que, sin embargo, ahora en la posguerra- afronta con especial empeño.

Así, cuando Treves escribe sobre los sociólogos (o proto-sociólogos) italianos de finales del siglo XIX, no los aprehende como elementos abstractos y asépticos del pasado cerrado, sino que los aprehende y promociona desde la posición subrepticia que mantenían, sin que esto suponga ningún tipo de maniobra especulativa con el bagaje teórico que proponían; se refiere esencialmente a juristas, filósofos positivistas como Brugi, Groppali o Miceli, «Lo studioso [de] il contributo che le scienze sociali possono dare allo studio del diritto [...] non può non pensare all'interese che negli ultimi anni del secolo scorso e nei primi di questo alcuni nostri giuristi sostenitori della filosofia positiva [...] hanno dimostrato di avere per questo argomento» ${ }^{2}$; pero del mismo modo Treves puntualiza: «mentre in altri paesi $i$ sociologi ebbero presente l'esempio del Comte che dimostrò sempre per il diritto una esplicita avversione e volle

\footnotetext{
${ }^{\text {I }}$ Véase a este respecto también TREVES (I973).

${ }^{2}$ «El estudioso [...] de las contribuciones que las ciencias sociales pueden ofrecer al estudio del derecho [...] no puede no pensar en el interés que en los últimos años del siglo pasado y en los primeros de éste algunos de nuestros juristas sostenedores de la filosofia positiva [...]han demostrado tener por este argumento». (trad. del autor)
} 
risolvere la scienza del diritto nella sociologia, in Italia $i$ sociologi seguirono l'esempio dell'Ardigò che dimostrò invece per il diritto una spiccata simpatia e volle risolvere la sociologia nella scienza del diritto (naturale)» ${ }^{3}$ (TREVES I962, 280).

Pero no solamente los positivistas italianos de finales del siglo XIX conservan el germen en formol de la sociología jurídica, sino que Treves también manifiesta la necesidad de renacimiento de esta ciencia en virtud de la no menos relevante tradición neokantiana -muy cercana a sus preocupaciones juveniles, a sus viajes a Marburgo, a sus encuentros con Kelsen...-. Sirve como estandarte de esta tradición en Italia la figura de del Vecchio.

Para Treves, tanto los positivistas como los neokantianos (irreconciliables en la metodología filosófica) convergen en el punto que interesa a nuestro propósito, es decir, en cuanto posibilitan -en contraste con el radicalismo idealista- la conformación autónoma de la sociología del derecho (TREVES I958, 526); Y recalca Treves el carácter autónomo basándose en la peculiaridad que distingue a la gran parte de los positivistas clásicos italianos de sus colegas: se distinguen de Comte, que resuelve el derecho en la sociedad, sin otorgarle al elemento jurídico capacidad de acción propia fuera de ésta; pero también difieren en ciertas puntualizaciones de Ardigò, que resuelve la sociedad en el derecho, otorgándole a éste capacidad orientadora para aquélla (TREVES I958, 528). Relativizando ambas posiciones, la mayoría de los positivistas italianos decimonónicos reconoce la independencia y la lógica interna de cada ámbito (derecho y sociedad) y disponen posibilidades de interacción entre ambos, con dinámicas distintas en función del caso.

Treves apunta que la tradición neokantiana no difiere apenas de las opiniones de los positivistas en este aspecto, de manera que buena parte de los juristas profesionales italianos (de formación neokantiana) aceptan y defienden la necesidad de tener en cuenta el concepto de sociedad en la formación del derecho -y viceversa-; de esta manera Treves exculpa a la tradición jurídica italiana de la típica acusación de impermeabilidad -cerrazón de inspiración kelseniana- que pudiera hacer inviable la interacción del sistema jurídico con otros sistemas sociales.

Estas consideraciones remiten en cierto modo (seguimos la línea lógica que Treves defiende en pro de la sociología jurídica) a la escuela histórica alemana del derecho, dentro de la cual Savigny desarrolla un doble nivel de relación del derecho con la sociedad: en un primer momento el derecho como derecho del pueblo, ordenamiento que emana de él en una formación «cultural» y voluntariosa continua; en un segundo momento -siguiendo una línea temporal y con el desarrollo de la economía y la especialización de las funciones sociales- el derecho como derecho del pueblo a través de sus agentes: políticos y juristas. Por esta razón, Savigny -así como la tradición positivista y neokantiana italiana- reconocen el componente técnico jurídico (la lógica formal del derecho) y el componente político que en Italia desdoblan los estudiosos en fenomenológico (origen y desarrollo del derecho) y deontológico (soporte ético del derecho). Desde esta taxonomía ya clásica, Treves valora el reconocimiento de las premisas que posibilitan la creación de una ciencia sintética para el estudio de la interrelación derecho/sociedad, pero también constata las carencias de los clásicos a la hora de enfrentar esta clasificación de los elementos formadores del derecho, ya que tanto positivistas como neokantianos sólo contemplan la influencia social en el elemento fenomenológico, dejando tanto la ética que precede al derecho como la lógica abstracta interna a él exentas por completo a la sociedad.

\footnotetext{
${ }^{3}$ «mientras en otros paises los sociólogos tuvieron presente el ejemplo de Comte, que demostró siempre una explícita aversión por el derecho queriendo resolver la ciencia del derecho en la sociología, en Italia los sociólogos siguieron el ejemplo de Ardigò, que demostró sin embargo por el derecho una evidente simpatía, queriendo resolver la sociología en la ciencia del derecho (natural)» (trad. del autor).
} 
Así, resume Treves, la tradición italiana prepara la disociación ${ }^{4}$ de los elementos que facultan a la sociología para aprehender el derecho y, de modo análogo, a la ciencia jurídica para tomar en consideración los factores sociales. Sin embargo debemos tener en cuenta (interpretamos así las conclusiones de nuestro autor) que la tradición referida aún lastra con la metafísica de los clásicos italianos: «se si pensa ai fini che $i$ positivisti e $i$ neokantiani si propongono di raggiungere [...] è facile rendersi conto del fatto che essi [...] si ispirano ad una concezione generale della scienza che potrebbe qualificarse in ampio senso come metafísica» ${ }^{5}$ (TREVES 1958, 540). Y es así, reafirmamos, si tenemos en cuenta que el dogmatismo defendido por estas corrientes de pensamiento en lo referente a determinados aspectos del derecho -y que lo sitúa en una posición invariable frente a factores sociales y por tanto materiales, físicos- sólo puede ser considerada, desde esta visión, como una postura metafísica.

En la misma línea de fomento de la sociología a través de una relectura del XIX italiano, destaca Treves una labor que sirve igualmente de fundamento histórico y que desarrollan básicamente etnólogos del derecho como Mazzarella, filósofos del derecho como De Marinis, Groppali, Vaccaro, Carle y Vanni o romanistas que, al cabo, en un país en el que no existen grandes referencias sociológicas (a diferencia del paradigma que Fustel de Coulanges, Durkheim, Bachufen, Ehrlich, Maine o Morgan marcan en otros países ${ }^{6}$ ), los estudios sobre el derecho romano resultan clarividentes en cuanto formulan una función que pone de manifiesto los factores extrajurídicos en el desarrollo del derecho; en cierto modo, en Italia, los estudiosos de un ordenamiento jurídico tan lejano en el tiempo son los sociólogos del derecho que, para dar sentido a las leyes romanas, las vinculan a la sociedad, a su estratificación, a sus cambios y a su evolución a lo largo de varios siglos de dominación latina. «Tra la seconda metà dell'ottocento e gli inizi di questo secolo, gli storici dei diritti antichi e delle istituzioni antiche, in particolare $i$ romanisti, hanno svolto una funzione decisiva, non soltanto entro $i$ confini della loro disciplina, ma anche nel porre le basi di una considerazione sociologica e antropologica del diritto» (TREVES I982b, IO).

Por último pone nuestro autor de relieve el trabajo del fundador de la sociología criminal, Enrico Ferri, «colui che per primo cercò di dare alla sociologia italiana una nuova speranza» ${ }^{8}$ (TREVES I962, 28I).

\section{3. Ámbito académico}

Junto a esta «reconstrucción de la razón» para el fomento de la sociología jurídica, debemos considerar de igual modo las razones de orden didáctico' ${ }^{9}$. Evidentemente, el

\footnotetext{
${ }^{4}$ En el sentido por el que diferencia teóricamente sus elementos, aunque su aplicación práctica no sea independiente.

${ }^{5}$ «Si se piensa en los fines que los positivistas y los neokantianos se proponen conseguir [...] es fácil darse cuenta de que se inspiran en una concepción general de la ciencia que podría calificarse en un sentido amplio como metafísica» (trad. del autor).

6 Treves les asigna la función por la que «posero le basi degli studi di sociología del diritto» (TREVES I982b, 8) es decir, por la que «pusieron las bases de los estudios de sociología del derecho» (trad. del autor).

${ }^{7}$ «Entre la segunda mitad del siglo XIX y los inicios de éste, los historiadores de los derechos e instituciones antiguas, en particular los romanistas, han desarrollado una función decisiva, no solamente dentro de los límites de su disciplina, sino también al poner las bases de una consideración sociológica y antropológica del derecho» (trad. del autor).

${ }^{8}$ «el primero que intentó dar a la sociología italiana una nueva esperanza» (trad. del autor)

${ }^{9}$ «Ragioni di ordine didattico» (TREVES I962, 284).
} 
desarrollo de una ciencia en la sociedad de funciones actual no tiene sentido ni posibilidades si no es a través de su normalización académica e investigadora. Por ello Treves da gran importancia a este factor:

La ausencia tanto de profesorado como de una cátedra en el ámbito sociológico se configura como estímulo de las investigaciones y trabajos ya iniciados dispersamente en la materia dada, ya que la profundización en ese ámbito puede dar lugar al reconocimiento académico, desde donde ejercer la docencia entendida como un método mediato para el proseguimiento en dichas investigaciones, ampliadas tanto en intensidad como en extensión a través de financiaciones públicas, grupos de trabajo y mayor coordinación. De este modo Treves resume: «la rinascita della sociologia in Italia iniziatasi e svoltasi in un primo tempo nel mondo del lavoro, è penetrata successivamente ed a fatica, ma in modo constante $e$ progressivo, anche nel mondo accademico. Prima della guerra, la sociologia era praticamente inesistente nelle università. Oggi esiste un piccolo numero di professori titolari e un numero considerevile di professori incaricati di sociologia. [...] dovrebbero sentire l'esigenza di insegnare la sociologia giuridica» ${ }^{\text {IO }}$ (TREVES, I962, 284). Es decir, reclamando el reconocimiento oficial de la autonomía de la sociología se colocan las bases para el recorrido teórico que relacione la sociología con el derecho.

Tras el reconocimiento de la primera cátedra de sociología a Camillo Pellizzi, surge la polémica por el sentido teórico que pueda tomar la institucionalización de la ciencia en el país, que, a juicio de Treves, puede desviarse peligrosamente de la dirección correcta que marca el elemento estrictamente científico ${ }^{\mathrm{II}}$ :

La polémica se concreta en posiciones enfrentadas en cuanto a la visión histórica de las incursiones sociológicas habidas en Italia; frente a una postura continuista defendida por Pellizzi, se sitúa la rupturista argumentada por $\operatorname{Treves}^{\mathrm{I} 2}$, aunque, como reconoce éste, la toma de posición en este asunto sólo es síntoma de un contraste más profundo ideológico y político. Esto se deduce de un breve repaso a algunos de los rasgos biográficos de Pellizzi que, licenciado en derecho, ocupa durante años la cátedra de «historia y doctrina del fascismo». Se acerca a las posiciones idealistas de Gentile y Carlini y colabora abiertamente con el régimen hasta el punto de ser nombrado presidente del Istituto nazionale di cultura fascista. Pasado el período dictatorial, Pellizzi es nombrado en I950 titular de la primera cátedra de sociología en Italia ${ }^{\text {I3 }}$, en la universidad de Florencia. Desde la autoridad de esta posición, defiende la tesis por la que el período fascista no supuso un paréntesis de negación de la sociología y que, más allá, la fomentó, si bien con distinta nomenclatura. Desarrolla su tesis a través de dos escritos ${ }^{\mathrm{I}}$ : en el primero de ellos Pellizzi se ocupa en principio de la tradición positivista italiana, «pasa por alto el idealismo» y destaca la labor de Pareto y Gini durante el fascismo, reconociéndole al corporativismo católico su labor en el

\footnotetext{
ro «El renacimiento de la sociología en Italia, iniciada y desarrollada en un primer momento en el mundo laboral, penetró sucesiva y esforzadamente, aunque en modo constante y progresivo, también en el mundo académico. Antes de la guerra, la sociología era prácticamente inexistente en las universidades. Hoy existe un pequeño número de profesores titulares y un número considerable de profesores encargados de sociología. [...] Deberían sentir la exigencia de enseñar sociología jurídica». (trad. del autor).

II «Treves urgió a una reforma de la enseñanza del derecho que consideró, con buenas razones, muy atrasada» (SAUQUILLO I993).

${ }^{12}$ «Col tramonto del positivismo e l'avvento dell'idealismo, si è verificata peró una profunda rotura fra la filosofia e la sociología e i filosofi idealisti sono riusciti a mettere al bando quest'ultima disciplina» (TREVES I960b, I79), es decir: «Con el ocaso del positivismo y la llegada del idealismo, se verificó una profunda ruptura entre la filosofía y la sociología, y los filósofos idealistas consiguieron solapar esta última disciplina» (trad. del autor)

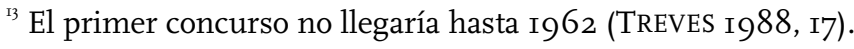

${ }^{\mathrm{I} 4}$ Véase, al respecto de esta polémica, TREVES (I99IC).
} 
desarrollo de la sociología. En el segundo de sus escritos (I958) viene a reafirmarse en su posición y, como le rescata Treves, «señala la importancia de estudiosos como Bottai, Spirito, Volpicelli y otros teóricos del corporativismo. Recuerda que en el período fascista fueron creadas las primeras facultades de ciencias políticas y se llevaron a cabo los primeros cursos de sociología. Indica que, si no hubo ningún nombramiento de profesor ordinario de la materia no fue debido al fascismo, sino a la oposición de personas que, como Benedetto Croce, eran hostiles al régimen. A excepción de Gramsci, señala, los antifascistas, en el período de la dictadura, no ofrecieron contribución alguna a los estudios sociológicos» (TREVES I99IC, I87).

Así, dos años después del regreso de Treves a Italia -con una carrera profesional reorientada hacia la sociología- éste se enfrenta al escollo -personal, profesional y científico- de que la primera cátedra de sociología italiana la ocupa un abierto colaborador del fascismo. El obstáculo para el desarrollo de la sociología del derecho es manifiesto si tenemos en cuenta los precedentes ideológicos y filosóficos que dirigen la acción de Treves, de manera que esta adversidad la canaliza a través de una respuesta a los artículos de Pellizzi, con la que trata de demostrar que el fascismo supuso una ruptura evidente con la tradición sociológica que, desde el siglo XIX, comenzaba a marcar una línea de evolución interrumpida por la filosofía dominante.

Para ello, nuestro autor analiza el positivismo italiano del XIX (al modo en que lo hemos abordado anteriormente) para detenerse en el neoidealismo y destacarle su dogmatismo a través del cual no pueden encauzarse investigaciones sociales de rigor. Aún con ello rescata Treves -al hablar de Benedetto Croce $^{15}-$ la función promocional del idealismo en la sociología, refiriéndose al historicismo como método para tener en cuenta factores extrajurídicos más allá de las interpretaciones subjetivas, idealistas. Concluye así negándole valor científico a las teorías corporativistas y muestra como síntoma de la ruptura la ampliación de horizontes y la continuidad con la tradición anterior al fascismo que supone el advenimiento de la democracia: destaca la importancia para el método científico de la libertad comunicativa, mostrando como ejemplo paradigmático de ello la creación en I948 del Centro nazionale di prevenzione e difesa sociale, pieza clave para el desarrollo de la sociología en Italia.

Dejado atrás este enfrentamiento crucial para el devenir de la línea sociológica predominante en los ambientes académicos, en I970 Renato Treves recibe el encargo de impartir el curso de sociología del derecho en la universidad de Milán ${ }^{16}$. Como dice Losano, en virtud de este nuevo puesto y del parágrafo final de sus Lezioni di filosofia del diritto (TREVES I969) titulado «Il filosofo del diritto e il sociologo del diritto», se señala un momento icónico: el paso decisivo de la filosofía del derecho a la sociología del derecho (LOSANO I998, I6). Un paso que hasta entonces venía siendo una suma de querencias y que ahora se completa cerrando el círculo en el campo académico, si bien la cerrazón definitiva se consuma en I977, año en el que Treves consigue la cátedra de sociología del derecho en la

\footnotetext{
${ }^{15}$ Con esto responde al modo manifiesto con el que Pellizzi acusaba en Croce aversión por la sociología, a pesar de la cual los científicos del régimen la sacaron adelante. A este respecto no es vano recordar una de las primeras obras de Treves acerca del filósofo italiano (TREVES I944).

${ }^{16}$ «los primeros encargos de enseñanza fueron otorgados en I969-70 y 70-7I respectivamente a Vittorio Frosini en Catania y a mi en Milán» (TREVES I988, I7).
} 
facultad de derecho de la universidad de Milán ${ }^{\text {r7 }}$, tras renunciar a la de filosofía del derecho que había ocupado durante casi treinta años, desde su regreso del exilior ${ }^{18}$.

\section{Primeras publicaciones tras el fascismo}

Desde esta nueva interpretación de la realidad italiana, Treves también analiza de modo crítico y con espíritu orientador las inquietudes que en el ámbito socio-jurídico empiezan a desencadenarse en Italia, sin perjuicio de denunciar la escasez de las mismas; las causas, además de las consabidas trabas del idealismo, las hace radicar Treves en los nuevos intereses encaminados hacia la sociología americana, «che si occupa ampiamente dei problemi dell'industria, dello sviluppo economico, dell'urbanizzazione, della stratificazione sociale e via dicendo, ma che si occupa assai poco dei problemi giuridici» ${ }^{19}$ (TREVES I962, 282), es decir, sociología eminentemente de campo y del todo distinta a las teorías positivistas italianas que pretendían una asunción integral, dibujando un universo teórico infalible. La sociología americana se identifica con un reconocimiento de la realidad social -un reconocimiento continuado pero no con la integridad de una ciencia metódica- tanto en las decisiones judiciales como en las argumentaciones de abogados y otros operadores jurídicos (con una evidente vinculación al common law), cuya síntesis pionera puede situarse en el alegato de Brandeis ante la Corte Suprema de los EEUU en I908 y cuyo principal sostenedor teórico es Roscoe Pound. Los nuevos intereses sociológicos en todos los países (pasando por el realismo jurídico escandinavo ${ }^{20}$ ) fijan su atención en este nuevo movimiento de corte antiformalista, tal vez de bases filosóficas endebles, pero de un pragmatismo irrevocable frente a la rigidez garantista de los códigos continentales. La recepción de este modo de sociología jurídica en el viejo continente -en Italia, en la parte que incumbe a la empresa de Treves- debe sin duda hacerse, debido a su sistema jurídico, modulado y en forma de variante adecuada, ya que no pueden extrapolarse las exigencias de «mirar a la realidad social» que se le imponen desde la cátedra a un juez anglosajón, al modo en que se le impondrían a los códigos continentales. En cierto modo la sociología americana trata de influir sobre comportamientos singulares, haciendo de los magistrados y abogados personas más sensibles a la sociedad ${ }^{21}$; esta misma fórmula debe aplicarse en el sistema continental no a personas, sino a procesos legales de composición de códigos y reglamentos.

Este movimiento, por tanto, lo asumimos para el caso que nos ocupa como influencia relevante en los primeros trabajos hacia la sociología del derecho en Italia, sin embargo no podemos entenderlo como factor para su autonomía, ya que en el ámbito formal no ofrece motivaciones para su categorización como ciencia independiente.

En esta línea Treves achaca a estas inclinaciones por la sociología que comenzaban a producirse en la Italia de posguerra errores de concepto, al no saber acoplar las teorías

\footnotetext{
${ }^{17}$ La cátedra de Sociología en Tucumán ya había dado este paso en cierto sentido, sin embargo, la docencia de la sociología jurídica en Italia y la cátedra de la misma materia suponen una culminación más voluntariosa que circunstancial.

I8 «la primera cátedra ganada por concurso fue otorgada a Vincenzo Tomeo en la facultad de ciencias políticas de la Universidad de Messina en I977» (TREVES I988, I7).

19 «que se ocupa ampliamente de los problemas de la industria, del desarrollo económico, del urbanismo, de la estratificación social, etc, pero que apenas se ocupa de los problemas jurídicos» (trad. del autor).

${ }^{20}$ Véase a propósito del realismo jurídico escandinavo: TREVES (1967, I38).

${ }^{21}$ Eran conocidos los defensores de esta postura como behavoristic, es decir, estudiosos del comportamiento humano, y era su intención extender a los jueces esta preocupación.
} 
formalistas del derecho (no en vano Treves introduce la obra de Kelsen en Italia) con la sociología jurídica ${ }^{22}$, confusión ésta que sobre todo los juristas deben saber superar para comprender la lógica irrefutable en la legitimación de la sociología del derecho como ciencia. Así rescata Treves las palabras de Ch. Eisenmann para acoplar la teoría formalista kelseniana con la sociología jurídica: «Kelsen ne dit pas non à la sociologie juridique, ne nie nullement la legitimitè ni l'interêt de ses problèmes et de son effort; il est loin de couper le contact entre ordre juridique et faits sociaux; mais il maintient entièremet la thèse du dualisme de nature de la science du droit et de la sociologie: la sociologie juridiche n'est pas la science du droit et la scienze du droit n'a pas à occuper de ses problèmes»" (TREVES I962, 286).

A pesar de los inconvenientes, Treves recoge los intereses por la sociología que, aunque dispersos y escasos, pueden estar empezando a apuntalar unos cimientos suficientes para la sustanciación de una ciencia. Desarrolla su labor mediante una serie no correlativa de artículos en los que trata de dar cierta organicidad a la dispersión de obras que se interesan por el asunto en liza. Para este análisis hemos compuesto un elenco de las publicaciones que, tras el fascismo, Treves considera de especial relevancia para sintomatizar el primer interés que los estudiosos italianos vuelcan sobre la sociología del derecho, conformando con este proceder, en principio a-sistémico, el regazo sobre el que debe descansar la institucionalización y compactación de la ciencia. Se trata, por tanto, del despunte de una disciplina en ciernes; se trata -aprovechando el argumento que nos ocupa- la constatación de un movimiento (social) que precede a su regularización (legal). Para ello componemos un elenco a través de la reconstrucción que Treves realiza en varios artículos (TREVES I958; 1962; I982b; I99Ib) y que da cuenta de su empeño en aras de fomentar el recibimiento definitivo de la ciencia sistémica sociojurídica ${ }^{24}$; destaca Treves: El ensayo de Giannini, sulla pluralità degli ordenamenti giuridici, además de sociologia e studi di diritto contemporaneo; Los trabajos de Ascarelli, señalando sus ganas por concentrar las investigaciones en la realidad jurídica efectiva, más allá del formalismo; La Bibliografia della sociologia italiana de Barbano e Viterbi, de importancia sustancial y simbólica por su compilación en 59 tomos referida a escritos sobre esta renovada forma de contemplar el fenómeno jurídico; El ensayo de Bobbio la mèthode sociologiche et les doctrines contemporaines de la philsophie du droit, en el que habla explícitamente de la sociología del derecho en Italia; La Sociologia del diritto de Filippo Barbano e Paolo Farneti, en la que distinguen entre sociología jurídica y jurisprudencia sociológica; El ensayo de Tozzi, filosofia del diritto, giurisprudenza normativa, giurisprudenza sociologia e sociologia della giustizia in Kelsen, en el que relaciona el formalismo kelseniano con la sociología del derecho; De Orestano, sociologie et ètude historique du droit, que introduce conceptos sociológicos en el estudio histórico del derecho; El ensayo de Nicola Matteucci, giurisprudenza analitica $e$ giurisprudenza sociologica; El ensayo de Gino Giugni, diritto e sociologia, en el que aboga por la vinculación entre la investigación sociológica y la jurídica; El ensayo de Scarpelli, il problema della definizione e il concetto del diritto; De Piero Calamandrei, su artículo «Elogio dei giudici scritto da un avvocato»; Avvocatura, de Candian; De Peretti Griva, esperienze di un magistrado; Los trabajos promovidos por el comitato di studio dei problemi dell'università italiana financiados por la Ford Foundation ${ }^{25}$; Las inchieste parlamentari (encuestas, sondeos),

${ }^{22}$ A este respecto destacamos la diferenciación entre experiencia jurídica y sociología jurídica, de modo que los alegatos por la primera descartan la defensa del formalismo jurídico, ya que se inclinan por la formación del derecho a través de la jurisprudencia en perjuicio de la rigidez legal; la sociología jurídica, sin embargo, resulta perfectamente compatible con sistemas jurídicos cerrados.

${ }^{23}$ «Kelsen no dice no a la sociología jurídica, ni niega en absoluto la legitimidad ni el interés de sus problemas y esfuerzo. Él está lejos de cortar el contacto entre el orden jurídico y los hechos sociales; sin embargo mantiene enteramente la tesis del dualismo de la naturaleza de la ciencia del derecho y de la sociología: la sociología jurídica no es la ciencia del derecho y la ciencia del derecho no debe ocuparse de sus problemas» (trad. del autor).

${ }^{24}$ Para las referencias de las obras relacionadas a continuación, véanse los artículos anunciados de Treves: TREVES (1958, I962, I982b, I991b).

${ }^{25}$ Ejemplo de la importancia de las relaciones italo-americanas. 
en funcionamiento desde la segunda mitad del siglo XIX, con evidente vocación de apoyo para la labor legislativa pero lejos de cualquier pretensión de sociología sistémica; Las investigaciones de l'asociazione per lo sviluppo industriale del Mezzogiorno; Las investigaciones de Adriano Olivetti, sobre el proyecto intermunicipal de Ivrea, continuado luego en el movimento di comunità; Las realizadas a través del programa Fullbright y de la sección «investigaciones sociales» de la Unesco, en las que colaboraban estudiosos italianos y americanos; Otras publicaciones periódicas como aggiornamenti sociali, la revista internazionali di scienze sociali, la revista nord e sud, la revista il mulino, quaderni di sociologia (Turín, I95I) y ragionamenti e opinione (aunque algunas de cierta tendencia izquierdista, ninguna vinculada al PCI, que en aquel entonces considera la sociología como tentáculo del imperialismo americano).

Destaca Treves igualmente la labor de Ricardo Bauer (TREVES I99Ie), presidente de la società umanitaria -en funcionamiento desde principios de siglo-, que llevó a cabo importantes investigaciones. Tras la guerra, ya bajo la presidencia de Bauer, se estimula la producción científica sociológica y fruto de la relación de la umanitaria con la universidad de Milán se destacan trabajos como la tesi di laurea de Tullio Savi, titulada ricerca sociale e riforma legislativa attraverso le esperienze di una istituzione. Le siguen relevantes investigaciones que se disponen como información para las reformas legislativas: en I953 sobre la situación del trabajador en la empresa industrial moderna, en I957 sobre el trabajo de la mujer y sobre los problemas de su inserción en las actividades productivas y en I959 sobre la reducción de los horarios de trabajo y sobre los problemas de la utilización del tiempo libre.

Del mismo modo pone de relieve nuestro autor la labor de Antonio Pigliaru, en concreto su obra la vendetta barbaricina come ordinamento giuridico (PIGLIARU I959), en donde se ocupa del «problema de la identificación y de la determinación de las reglas consuetudinarias que, de acuerdo con una antigua tradición, están en la base de comunidades espontáneas organizadas de manera autónoma» (TREVES, I99If), y lo hace a través del estudio de las gentes que viven en las montañas del centro de Cerdeña, en Barbagia $^{26}$. Mediante expresiones de las gentes, textos de literatura popular o episodios significativos que los barbaricinos cuentan en entrevistas, Pigliaru redacta el «código de la venganza», verdadero ordenamiento jurídico al margen del oficial.

Por último, no olvida nuestro autor la labor del Istituto Sturzo ni de los primeros trabajos del Centro nazionale di prevenzione e difesa sociale.

Como puede comprobarse en el elenco, la multiplicidad de escritos e iniciativas pronostica la viabilidad de la empresa sociológica y da cuenta de la suficiencia inicial de recursos intelectuales para emprenderla. Treves sirve a este respecto de elemento de cohesión en pro de la diferenciación de la sociología jurídica.

\section{Movimiento asociativo}

Treves aborda esta cuestión bajo la etiqueta del «problema asociativo» ${ }^{27} \mathrm{y}$, desde aquellos primeros años de obras dispersas hasta los últimos años de su vida, es su preocupación la de conformar una unión que otorgue un salvoconducto de garantía a la ciencia en formación: «desiderio, vivamente sentito da tutti, di associarsi, di incontrarsi, di

\footnotetext{
${ }^{26}$ Véase también TREVES (I982a).

${ }^{27}$ Así lo llama, años después, en su discurso inaugural de la Convención italiana de sociología, el I5 de octubre de i98I en el Campidoglio de Roma: (TREVES i98I).
} 
informarsi reciprocamente delle propie ricerche, di discutere problemi di comune interesse e di coordinare un lavoro spesso disordinato e disperso» ${ }^{28}$ (TREVES I98I, 727).

Reproducimos aquí la reconstrucción que Treves hace de los momentos fundamentales en la conformación de la estructura asociativa de la sociología del derecho italiana. A estos efectos «Trent'anni di sociologia in Italia e il problema asociativo» (TREVES I98I) es el artículo que sirve de fundamento formal para este epígrafe, ya que en él Treves repasa desde la madurez el recorrido institucional italiano en búsqueda de la composición de una ciencia: asociaciones que muestran el interés investigador, congresos, convenciones, docencia, reconocimiento institucional... en cierto modo, funciones sociales que se derivan de una estructura interna científica suficientemente arraigada y que, al mismo tiempo -en mutualidad no necesariamente simétrica- reinvierten en la profundización de dicha estructura interna y, por tanto, reinvierten en la investigación y en el mejor conocimiento del objeto de la ciencia ${ }^{29}$.

Por lo tanto configuramos a continuación un cuadro histórico tomando las referencias que Treves señala como puntos delimitadores de la línea que, en definitiva, resuelve el «problema asociativo». Estas referencias las recoge básicamente en tres artículos (TREVES I98I; I986; I99Ib) que completamos con las aportaciones de otros estudiosos (TANZI I997; LOSANO I998).

Escribe Treves en el primero de los artículos en cuestión que, en el mundo académico, puede constatarse alguna señal esporádica y aislada de apertura a la nueva disciplina en los años cincuenta; Recapitulamos: En I95I la fundación de los Quaderni di sociologia en Turín, a cargo de Abbagnano y Ferrarotti. En I95I la fundación del Istituto Sturzo en Roma ${ }^{30}$. En I954 destaca Treves la organización en Bolonia de la convención sobre «filosofía y sociología» por parte de Il Mulino ${ }^{31}$, así como del Congreso internacional en Milán sobre el problema de las áreas atrasadas, proyectado por el Centro Nazionale di prevenzione e difesa sociale (Il Centro) abordando la falta de desarrollo industrial y social en determinadas regiones de los Alpes, del delta padano y, sobre todo, de la Italia meridional. «En I956, el congreso internacional de defensa social marca el comienzo de continuados encuentros y congresos inspirados en la docrina de la nuova difesa sociale, una doctrina que se inserta en el marco del estado asistencial y que en 1963 encuentra su órgano de profundización y difusión en la revista Cahiers de défense sociale, publicada regularmente por il Centro» (TREVES I99Ib, I74).

Sin embargo, aunque la activación asociativa para el intercambio de ideas en el ámbito sociológico ya puede darse por iniciada en los comienzos de los cincuenta, Treves aún echa en falta un ente de liderazgo suficiente como para vincular y servir de referencia

\footnotetext{
${ }^{28}$ «deseo sentido por todos de asociarse, de encontrarse, de informarse reciprocamente de las propias investigaciones, de discutir problemas de común interés y de coordinar un trabajo a menudo desordenado y disperso» (trad. del autor).

${ }^{29}$ «È evidente che l'università italiana potrebbe contribuire [...] promuovendo la ricerca scientifica disinteresatta e fornendo punti di riferimento sicuri e mexxi di controllo veramente eficaci a tutti coloro che operano in qualità di sociologi nel mondo del lavoro, della politica e della pubblica amministrazione» (TREVES I960b, I75).

${ }^{30}$ «L'Istituto Luigi Sturzo è un ente morale fondato nel 1951 e intitolato a Luigi Sturzo, fondatore nel 1919 del Partito Popolare Italiano e tra gli artefici del primo movimento democratico cristiano. Svolge attività di ricerca e di formazione nel campo delle scienze storiche, sociologiche, politiche ed economiche», en www.sturzo.it (web oficial, febrero de 2007), es decir: «"El Instituto Sturzo es un ente moral fundado en I95I y dedicado a Luigi Sturzo, fundador en I9I9 del Partito Popolare Italiano y entre los artífices del primer movimiento democristiano. Desarrolla actividades de investigación y formación en el campo de las ciencias históricas, sociológicas, políticas y económicas» (trad. del autor).
}

${ }^{3 \mathrm{I}}$ Revista y asociación fundadas en I95I. 
común a las distintas iniciativas. En un primer momento esta entidad se concretó en la asociación Il Mulino, ya que con su impulso en 1957 se convoca en Bolonia la asamblea en la que se funda la Associazione italiana di scienze sociali (AISS), es decir, la primera asociación italiana con vocación de continuidad y con objeto plenamente sociológico, más allá de coyunturas y casualidades. El relevo a Il Mulino desde el enfoque referencial que le otorgamos lo toma precisamente il Centro a partir de $1958^{32}$, año en el que organiza en Milán el I Congreso nacional de ciencias sociales, a cuyo término tiene lugar la constitución formal de la AISS. Como sabemos -y como recuerda Tanzi en su ensayo referido- el papel de Treves en esta primera etapa de consolidación institucional se desarrolla en un primer plano, ya que nuestro autor es nombrado presidente de dicha asociación y, por tanto, impulsor imprescindible de aquel I Congresso nazionale di scienze sociali.

En I959 tiene lugar en Stresa (localidad cercana a Milán) el IV Congreso mundial de sociología en el que participan más de ochocientos sociólogos de varios países. La responsabilidad de su organización recae en la AISS y en il Centro, y la solvencia demostrada supone sin duda una confirmación de la capacidad italiana para la prosecución de la empresa sociológica también a nivel institucional. El propio Ministro de Instrucción Pública italiano, Giuseppe Medici, incide en el éxito del congreso sociológico, organizado por un país en el que, según sus propias palabras, no faltan los estudiosos de valor en este ámbito pero sí las cátedras que éstos deberían ocupar. El congreso sirve, por tanto -en el plano social, no esencialmente sociológico- para reflejar la situación discordante entre el vigor con el que comienzan las investigaciones en Italia y la ausencia de reconocimiento oficial de éstas. Treves destaca igualmente la importancia de dicho congreso mundial en cuanto Italia consigue por primera vez tener un representante en el Comité directivo y en el Consejo de la Asociación internacional de sociología.

En cuanto a las aportaciones sustanciales en el congreso de Stresa, Tanzi destaca el documento presentado por Treves (TANZI I997, 68) en el que trata de dar a conocer oficialmente una sociología italiana ligada a la resistencia antifascista y desvinculada, por consiguiente, de cualquier vestigio mussoliniano ${ }^{33}$. Trata así nuestro autor de presentar, a modo de manifiesto, una generación democrática de sociólogos italianos capaz de entrar en la dinámica internacional de la disciplina. De este modo, la relevancia del congreso de Stresa sirve de punto de inflexión en la relación entre la ciencia en ciernes italiana con la sociología de los demás países, muchos de los cuales habían podido desarrollarla sin las trabas propias de la política y la tradición filosófica adversas.

Al año siguiente, en I960, tiene lugar en Milán un nuevo congreso de carácter internacional sobre el progreso tecnológico y la sociedad italiana en transformación, dando cuenta del asentamiento efectivo que el método sociológico toma en Italia.

Ese mismo año, y de modo tangencial a este epígrafe aunque recogiéndole el simbolismo, Treves publica «Considerazioni intorno alla sociologia giuridica» (TREVES I96oa), que, en opinión de Losano, es su primer escrito dedicado íntegramente a la sociología del derecho; por esto consideramos el aporte institucional -en cuanto a su función en el desarrollo de la disciplina- que se le desprende a este artículo.

«Significativo e importante fu, a mio modo di vedere, il Convegno tenutosi ad Ancona» ${ }^{34}$ (TREVES I98I, 729); así distingue Treves esta convención nacional desarrollada entre I96i y

${ }^{32}$ También, en opinión de TREVES (I99Ib, I8I), deben destacarse otras organizaciones: Istituto lombardo di studi economici e sociali (constituido en I960), Istituto regionale di ricerca della Lombardia (1974), Istituto per la ricerca della pubblica amministrazione, il Consiglio italiano per le scienze sociale (1974) o il Centro di studi investimenti sociali (1964).

${ }^{33}$ Valga aquí recuperar su polémica con Pellizi, en TREVES (I99IC).

${ }^{34}$ «Significativo e importante fue la Convención celebrada en Ancona» (trad. del autor). 
I962 en el que se discute el problema de las relaciones entre los sociólogos y los centros de poder en Italia, lo que hace patente la trascendencia que a la profesión se le desprende hacia otros ámbitos desde la esfera más cerrada inicial. En la convención, impulsada también por il Centro y la AISS, recuerda Treves que la opinión se orienta hacia un modelo ideal de sociólogo por el que éste trata de evitar el peligro tanto de someterse al poder como de recluirse en su «torre d'avorio»; un sociólogo ideal, por tanto, que debe conocer la realidad que lo circunda para proponer las elecciones racionales más avanzadas. «L'opinione prevalente fu quindi essenzialmente orientata verso l'ideologia riformista che si presentava allora come una ideologia progressista in armonia con quella del centro-sinistra» (TREVES I98I, 729). En estas intenciones renovadas, Treves señala un nuevo aliento -reformista- para la consecución de dos grandes investigaciones sobre la sociedad italiana: la primera sobre la escuela (que genera la publicación de I8 volúmenes en I964) y la segunda, en la que el propio Treves ejerce tareas directivas, sobre la administración de justicia italiana.

Esta última investigación a su vez propone, en la concreción ofrecida, un tema de trabajo para las futuras reuniones de los sociólogos italianos. Los io volúmenes engendrados en aquella investigación son objeto del interés de los sociólogos, creando una tendencia entre los profesionales que Treves significa otorgándole el mérito de introducir en la cultura italiana una materia nueva: la sociología del derecho ${ }^{35}$.

Pero antes de este otro momento icónico, no podemos dejar de referirnos a la perseverancia de los sociólogos italianos que, durante 1962 , siguieron cultivando y avivando el desarrollo de su ciencia: Treves presenta su documento discutido en Ancona sobre sociólogos y centros de poder en el $\mathrm{V}$ congreso mundial celebrado en Washington; es nombrado vicepresidente de la Asociación internacional de sociología y presidente del Comité internacional de sociología del derecho fundado ese mismo año por William Evan y Adam Podgorecki ${ }^{36}$. Como se puede comprobar, Renato Treves ya no es tan solo el principal impulsor del renacimiento de la sociología en Italia, sino también un relevante espoleador de la sociología a nivel mundial a través de su participación asociativa.

Aún en $1_{962}$ se funda en Trento el Istituto superiore di sociologia y tiene lugar el primer concurso a cátedra de sociología, tras el cual «i concorsi della materia si susseguirono a ritmo accelerato creando un corpo di professori destinato ad avere un peso sempre maggiore nel mondo académico» ${ }^{37}$ (TREVES I98I, 729). La estabilización de la sociología general es ya un hecho incluso en el ámbito académico ${ }^{38}$, lo que sirve de índice para calibrar la relevancia de la ciencia implantada ${ }^{39}$.

Sin embargo, para hablar de sociología jurídica -que en el plano teórico se aborda de modo natural desde la sociología general, sin originalidades trascendentes y mediante procesos lógicos evidentes- debemos remitirnos a aquel momento icónico referido y que en I964 se manifiesta desde la investigación promovida por il Centro y dirigida por Treves. Un año mas tarde, en 1965, se publica un número especial de los Quaderni di sociologia que Treves dedica a la sociología del derecho, señalando con ello -tomamos la opinión de Losano- el nacimiento oficial de esta disciplina en Italia. A partir de ese mismo año, Renato

${ }^{35}$ «a mi modo de ver, un primer paso de cierta importancia en el camino hacia la sociología del derecho se consiguió con la investigación sobre la administración de la justicia en la sociedad italiana en transformación organizada por el Centro en I962» (TREVES I988).

${ }^{36}$ Véanse las primeras conclusiones de este Comité en TREVES (1965).

${ }^{37}$ «los concursos de la disciplina continuaron a ritmo acelerado creando un cuerpo de profesores destinado a tener un peso siempre mayor en el mundo académico» (trad. del autor).

${ }^{38}$ Véase al respecto TREVES (1960b)

${ }^{39}$ El hecho se sustancia aún más en el primer concurso a cátedra de Sociología general en I962, «año en el cual fueron nombrados los primeros tres catedráticos de la disciplina» (TREVES I988, I7). 
Treves comienza a publicar con regularidad en Edizioni di comunità la columna «Diritto e cultura moderna», dando así un nuevo paso en la normalización y vocación de permanencia de la sociología jurídica.

Mientras estos momentos de conquista institucional -como estandartes- van marcando el terreno ganado, los congresos y convenciones siguen su curso ya casi mecánico: en I964 se celebran las convenciones internacionales de Saint Vicent y en ig66 el congreso mundial de Evian, en donde se puede constatar, escribe Treves, «che la sociologia italiana era ormai cresciuta alla pari della sociologia degli altri paesi e occupava stabilmente il suo posto sul piano nazionale e su quello internazionale» ${ }^{40}$ (TREVES I98I, 729). En 1967, sin embargo, se producen una serie de convulsiones relevantes que, a nuestro entender, reflejan no ya una crisis de la configuración científica de la sociología, sino los avatares propios de toda institución asentada: política interna en definitiva; el nuevo clima cultural italiano apunta un nuevo frente de crítica que embiste la sociología reformista institucionalizada en los años anteriores. Los movimientos de izquierdas consideran la sociología reformista como un modo de estabilización del sistema y, en ese clima, la AISS deja de tener el carácter vanguardista que en cierto modo suponía su leiv motiv. Sumamos a esto su alejamiento del Centro nazionale di prevenzione e difesa sociale y concluimos con Treves que la Asociación italiana de estudios sociales «non poteva più svolgere in modo incisivo la sua attivitá», extinguiéndose por tanto ${ }^{41}$.

Sin embargo la actividad sociológica continúa más allá de problemas internos, como una ciencia con función asignada independientemente de una u otra estructura. En I967 es nombrado secretario de la Asociación internacional de sociología Angelo Pagani, lo que devuelve el prestigio puesto en duda tras la división de los sociólogos italianos.

En I970 Pagani organiza el congreso mundial de Varna (ciudad italiana de los Alpes orientales) en el que se produce una aportación importante bajo la presidencia del polaco Szczepanski: la Asociación internacional abre sus puertas a los investigadores de países socialistas.

A Pagani le sucede Guido Martinotti (continúa así la secretaría italiana tras la prematura muerte de Pagani ${ }^{4^{2}}$ ), quien organiza el Congreso mundial de Toronto. Treves hace hincapié en la gran aportación italiana a este congreso, quizá empañada por la indefinición de su órgano representativo en el consejo de la Asociación internacional. En ausencia de la AISS, el debate sobre el modo de reorganización era esencial para un correcto desarrollo de las investigaciones sociológicas en Italia.

El mismo año de I974, y con el escenario de la falta de centralización organizativa en Italia, Renato Treves funda la revista cuatrimestral Sociologia del diritto; la única revista italiana de la materia y en la que Treves trata -en opinión de Tanzi- de abrir el debate sobre la naturaleza y objetivos de la disciplina desde una posición abierta a distintas concepciones. No se trata, por tanto, de una revista tendenciosa, no se trata de una publicación que siente bases científicas, sino una publicación para el debate. La revista trata de revertir aún con más ahínco en la estabilización de la disciplina en Italia, tomando la disciplina como un todo independientemente de las variantes internas que, evidentemente, existen.

\footnotetext{
$4^{\circ}$ «que la sociología italiana había ya crecido hasta igualar la sociología en otros paises y ocupaba con estabilidad su sitio en el plano nacional e internacional» (trad. del autor).

${ }^{4 \mathrm{r}}$ «ya no podía desarrollar ya en modo incisivo su actividad» (trad. del autor). La AISS intenta reconstruirse en I97I, pero la contestación de los jóvenes sociólogos, con pretensiones demasiado distintas a las originales del Centro, lo hace imposible.

${ }^{42}$ En el décimo aniversario de su muerte, Treves le dedica un emotivo discurso que da cuenta de la relevancia de Pagani (TREVES I99I,d)
} 
Pero las publicaciones y el desarrollo de investigaciones sobre sociología no colman el vacío institucional que deja la desaparición de la AISS. Tras el congreso de Toronto la secretaría de la Asociación internacional pasa de Italia a Canadá que exige la definición institucional de las asociaciones nacionales italianas. Il Centro es el encargado de constituir un Comitato di coordinamento que desde I977 representa a Italia en el consejo de la Asociación internacional de cara al congreso de ese mismo año en Uppsala, si bien con vocación temporal.

En I979 se convoca en Milán la convención sobre la sociedad industrial metropolitana y los problemas del área milanesa. Tras varios años de ausencia de reuniones entre los sociólogos italianos, éstos tratan, en vano, de constituir una nueva asociación nacional.

El problema asociativo, como vemos, sigue abierto y a medida que avanzamos en el tiempo el problema deja de tener el sentido originario que le buscamos en estas líneas para convertirse en un problema avanzado de política institucional; sin embargo, y en lo que concierne a este artículo, quedan sentadas las bases que describen la dinámica que, tras la guerra, imbuye a la sociología italiana en la búsqueda de una institucionalización frente la dispersión absoluta que la precedía. Solventado este problema, en los años ochenta, la institucionalización deja de ser una fase del desarrollo de la sociología (en el sentido científico) para transformarse más en un problema de estructura interna. Queda patente del mismo modo la labor fundamental que en esta línea desarrolla Renato Treves: interviene con relevancia en los distintos congresos y convenciones, tanto con reivindicaciones científicas como con alegatos a la propia organización de la ciencia; se refiere, con vocación de trascendencia, al nacimiento de la sociología jurídica en Italia; ocupa cargos de relevancia en las distintas organizaciones que dan soporte logístico a la propia ciencia; uno de los primeros docentes y catedrático de sociología del derecho en Italia; fundador y director de la única revista socio-jurídica italiana... En definitiva, se convierte en el principal promotor de la autonomía de la ciencia sociológica primero y de la sociojurídica después, reivindicando los elementos académicos e institucionales que esta autonomía conlleva.

\section{Conclusiones}

Con estos breves apuntes hemos pretendido conformar una idea general de la importancia de Renato Treves en el origen institucional de la sociología jurídica en Italia. Desde la descripción de sus actuaciones concretas hemos tratado de dar relieve a una figura que, con el paso del tiempo y con el asentamiento de la disciplina sociojurídica, irá adquiriendo las cotas de significación que aquí hemos apuntado: recompone los precedentes y la tradición jurídica y filosófica italiana para poder insertar de manera lógica la posibilidad sociojurídica; reconduce, frente a la rémora del pasado fascista, la dirección que en los primeros años de democracia comenzaba a tomar en el plano académico la disciplina sociológica; recopila y trata de dar cierta unidad -sin perjuicio de una crítica reorientadora- a la multiplicidad de publicaciones inscribibles en el ámbito sociojurídico; estimula y fomenta la asociación y la colaboración de todos los sociólogos del derecho italianos, factor indispensable para el éxito de la disciplina.

Se trata, por tanto, de una labor fundamental en los orígenes de la sociología del derecho en Italia, labor que, entrado el siglo XXI, sin duda transciende los límites nacionales para hacer de Renato Treves una referencia internacional inexcusable. 


\section{Bibliografía citada de Renato Treves:}

(I944): Benedetto Croce, filosofo de la libertad, Buenos Aires: ed. Iman.

(I958): «Il contributo delle scienze sociali allo studio del diritto», Rivista internazionale di filosofia del diritto XXXV (5), pp. 526-543.

(I960a): «Considerazioni intorno alla sociologia giuridica», Rivista trimestrale di diritto $e$ procedura civile I, pp. I69-I77.

(I960b): «La sociologia nelle universitá italiane», Quaderni di sociología 37, pp. I73-I80.

(I962): «La sociologia giuridica in Italia e i suoi possibili sviluppi», Quaderni di Sociologia XI (3), pp. $280-297$.

(I965): «Sociologia del diritto e diritto comparato», Quaderni di Sociologia XVI (3), pp. 376392.

(I967): «Recenti sviluppi della sociologia del diritto in Europa», Quaderni de sociologia XVI (2), pp. I46-I64.

(1969): Lezioni di filosofia del diritto: appunti ad uso degli studenti : anno accademico 19681969, Milano: La goliardica.

(I973): «La sociologia del diritto in Italia», Rivista internazionale di filosofia del diritto XLIII (2), pp. 409-435.

(I98I): «Trent’anni di sociologia in Italia e il problema asociativo», Quaderni di Sociologia XXIX (4), pp. 727-73I.

(I982a): «Considerazioni su la vendetta barbaricina come ordinamento giuridico», en Studi in onore di Antonio Amorth, Milano: Giuffrè, vol. 2, pp. 6I8-624.

(I982b): «Lo studio dei diritti antichi e le origini della sociologia del diritto in Italia», Sociologia del diritto IX (3), pp. 7-I4.

(I986): «Sociologia del diritto oggi e crisi dello stato sociale», Sociologia del diritto XIII (2-3), pp. 247-260.

(I988): «Un camino hacia la sociología del derecho», en BERGALLI, R. (Coord.), El derecho y sus realidades: investigación y enseñanza de la sociología jurídica: Jornadas sobre la Investigación y la Enseñanza de la Sociología Jurídica (Barcelona, 7-9 abril de 1988): homenaje a Renato Treves.

(I991a): Sociología del derecho y socialismo liberal, Madrid: Centro de Estudios Constitucionales.

(I99Ib): «El renacimiento de la Sociología en Italia» en TREVES (I99ia, I7I y ss), sobre la intervención en el Congreso «la società italiana in trasformazione al traguardo del 2000» en Milán (1984).

(I99IC): «Continuidad o ruptura en la historia de la Sociología» en TREVES (I99Ia, I85 y ss.). 
(I99Id): «Angelo Pagani y la primera cátedra de Sociología en Milán» en TREVES (I99ia, I9I y sS), discurso (I982) en la Facultad de Ciencias políticas de Milán por el décimo aniversario de la muerte de Pagani.

(I99Ie): «Ricardo Bauer: socialismo e investigaciones empíricas» en TREVES (I99Ia, I95 y Ss.)

(I99If): «Antonio Pigliaru y la sociología empírica del derecho» en TREVES (I99Ia, 203 y ss.)

\section{Bibliografía citada de otros autores:}

Losano, M.G. (I998): Renato Treves, sociologo tra il vecchio e il nuovo mondo, Milano: Edizioni Unicopli.

PigliARU, A. (I959): La vendetta barbaricina come ordinamento giuridico, Milán: Giuffrè.

SAUQUILlO, J. (I993): «Recuerdo de Renato Treves (I907-I992): líneas fundamentales de su pensamiento jurídico y político», Sistema: Revista de ciencias sociales II2, I993, pp. II7I28.

TAnZI, A. (I997): Renato Treves. Dalla filosofia alla sociologia del diritto, Napolí: Edizioni Scientifiche Italiane. 